\title{
Novos táxons de Aerenicini (Coleoptera, Cerambycidae, Lamiinae) da Guatemala, Brasil e Bolívia
}

\author{
Ubirajara R. Martins ${ }^{1,3}$ \& Maria Helena M. Galileo ${ }^{2,3}$
}

\author{
1. Museu de Zoologia, Universidade de São Paulo, Caixa Postal 42494, 04218-970 São Paulo, SP, Brasil. \\ 2. Museu de Ciências Naturais, Fundação Zoobotânica do Rio Grande do Sul, Caixa Postal 1188, 90001-970 Porto Alegre, RS, \\ Brasil. \\ 3. Pesquisador do CNPq
}

\begin{abstract}
New taxa of Aerenicini (Coleoptera, Cerambycidae, Lamiinae) from Guatemala, Brazil and Bolivia. New genus described: Suipinima gen. nov., type species, S. suturalis sp. nov., from Brazil (Rondônia) and Bolivia (Santa Cruz). New species described from Bolivia (Santa Cruz): Suipinima pitanga sp. nov., S. una sp. nov., $S$. marginalis sp. nov., Antodice opena sp. nov., Antodilanea auana sp. nov., Aerenicopsis angaibara sp. nov.; from Guatemala: Aerenicopsis irumuara sp. nov. Key to the species of Suipinima is added.
\end{abstract}

KEYWORDS. Aerenicini, Antodice, Antodilanea, Aerenicopsis, Suipinima.

\section{INTRODUÇÃO}

A tribo Aerenicini foi revista por MARTINS \& GALILEO (1998) e reúne 26 gêneros neotropicais. Após a revisão, Martins \& Galileo (2003) descreveram uma espécie em Antodice Thomson, 1864. O material enviado por J. E. Wappes permitiu a descrição de um gênero inédito e de espécies novas em Antodice Thomson, 1864, Antodilanea Gilmour, 1962 e Aerenicopsis Bates, 1885.

O material utilizado é proveniente das seguintes coleções (responsáveis e abreviaturas entre parênteses): American Coleoptera Museum, Bulverde, Texas (James E. Wappes, ACMB); Museu Nacional, Rio de Janeiro (Miguel A. Monné, MNRJ); South African National Collection of Insects, Pretoria (Elizabeth Globbelaar, SANC). Por intermédio de J. E. Wappes, examinou-se material da Florida State Collection of Arthropods, Gainesville (FSCA) e foi por ele determinado que os holótipos contidos na sua coleção (ACMB) fossem depositados no Museo de Historia Natural Noel Kempff Mercado, Santa Cruz, Bolívia (MNKM).

Também estão citadas no texto as coleções do Museu de Ciências Naturais, Fundação Zoobotânica do Rio Grande do Sul, Porto Alegre (MCNZ) e do Museu de Zoologia, Universidade de São Paulo, São Paulo (MZSP).

\section{Antodice opena sp. nov.}

(Fig. 1)

Etimologia. Tupi, opêna $=$ quebrado. Alusivo ao estado de má conservação do holótipo.

Tegumento de maneira geral alaranjado. Tegumento preto: escutelo, lado externo do escapo, ápice externo dos antenômeros IV e V, prosterno, mesosterno, base do metasterno, meio dos urosternitos I e II. Tegumento amarelado: antenômeros III a V (menos o lado externo do ápice do IV e do V) e pernas. Antenômeros III e IV com pêlos pretos, mais concentrados no ápice. Cabeça revestida por pubescência amarelada, esparsa; no vértice, duas manchas pequenas de pêlos escuros localizadas atrás dos lobos oculares superiores e no limite com o occipício. Pronoto com pubescência alaranjada e desenhos irregulares de pubescência branca; duas manchas glabras nos lados da metade posterior. Prosterno e partes laterais do protórax com pubescência predominantemente esbranquiçada. Élitros com pubescência alaranjada; pubescência branca: no sexto basal, em pequena faixa interrompida, oblíqua em sentido descendente da margem para a sutura; grande área na metade apical que anteriormente avança pela sutura e termina pouco antes do ápice. Além disso, os élitros têm, principalmente no meio, pequenas manchas irregulares pretas. Ápices dos élitros com pêlos alaranjados mais longos que a pilosidade geral. Face ventral coberta por pubescência esbranquiçada, menos no metasterno, onde está mesclada de alaranjado e branco. Tíbias com pêlos longos, esparsos, no lado externo.

Dimensões em mm, ơ. Comprimento total, 8,0; comprimento do protórax, 0,9 ; maior largura do protórax, 1,2; comprimento do élitro, 5,6; largura umeral, 1,6.

Material-tipo. Holótipo ơ, BOLÍVIA, Santa Cruz: Buena Vista (410 m), 29.X.1999, C. Porter \& L. Stange col. "disturbed tropical transition forest" (MNKM).

Discussão. Acompanham o holótipo, colados em cartão, o escapo, o pedicelo e os antenômeros III-V. Antodice opena sp. nov. distingue-se de todas as espécies de Antodice pelo padrão de colorido dos élitros; pelo mesonoto e escutelo pretos; pelo escapo bicolor; pelos antenômeros III e IV enegrecidos no lado externo do ápice e providos de pêlos pretos e abundantes.

\section{Antodilanea auana sp. nov.}

(Fig. 2)

Etimologia. Tupi, aûana $=$ bracelete. Alusivo às faixas de pubescência amarelada que ornamentam os élitros.

Tegumento de maneira geral preto; áreas castanhoamareladas: antenômeros III-VII exceto a região apical; antenômeros VIII, IX exceto metade apical; pernas menos área basal dos profêmures; anel no meio dos 
mesofêmures; metafêmures exceto anel apical. Pubescência amarelada, grossa, densa; mais concentrada formando faixa longitudinal, visível de acordo com a incidência da luz, de cada lado do pronoto; nos élitros, faixas bem definidas na sutura, prolongadas por faixas oblíquas, descendentes da sutura para a margem, uma no meio, outra no quarto apical e uma pequena faixa no ápice. Sexto apical dos élitros com mancha de pubescência preta no ápice junto da sutura. Face ventral com pubescência amarela, grossa, no prosterno, mesepimeros, metepimeros, metepisternos, lados do metasterno, lados e margem posterior dos urosternitos. Escutelo, mesosterno, centro do metasterno e dos urosternitos e pernas, com pubescência amarelada, fina, visível de acordo com a incidência da luz. Antenas apenas mais longas que o corpo. Escapo e pedicelo com pubescência amarelada, densa, grossa; flagelômeros com pêlos da cor do tegumento, mais longos na margem interna. Borda apical do último urosternito largamente emarginada.

Dimensões em mm, Comprimento total, 11,0; comprimento do protórax, 1,5; maior largura do protórax, 1,9; comprimento do élitro, 8,3; largura umeral, 2,7 .

Material-tipo. Holótipo §', BOLÍVIA, Santa Cruz: Buena Vista (4-6 km SSE, Hotel Flora \& Fauna), 17-19.X.2000, Wappes \& Morris col. (MNKM)

Discussão. Antodilanea auana sp. nov. distingue-se de $A$. modesta (Lane, 1939), única espécie conhecida do gênero até agora, pelas dimensões maiores, pelas faixas oblíquas de pubescência nos élitros e pela mancha preta no sexto apical dos élitros junto à sutura. Em A. modesta, o comprimento dos machos é de 7,9 a $8,9 \mathrm{~mm}$, a pubescência elitral não constitui faixas e o ápice elitral não tem mancha de pêlos pretos.

\section{Aerenicopsis angaibara sp. nov. (Fig. 3)}

Etimologia. Tupi, angaibara $=$ magro. Alusivo ao corpo esbelto.

Tegumento preto exceto pernas e antenômeros V-XI, castanho-avermelhados. Pubescência esbranquiçada concentrada em faixas estreitas: dos tubérculos anteníferos ao occipício; da área acima da emarginação entre os lobos oculares até a borda anterior do protórax; em continuação, de cada lado do protórax; no lado externo dos mesepisternos e mesepimeros; lado interno dos metepisternos; metade centro-posterior do prosterno, em continuação no processo prosternal, no centro do mesosterno, no processo mesosternal e no centro do metasterno; no centro do pronoto; no escutelo; em cada élitro, faixa dorsal paralela à sutura, mais alargada no terço apical, faixa látero-dorsal no terço basal, faixa lateral nos dois terços apicais fundida com a faixa dorsal na região apical, faixa junto à margem no quarto basal; no abdômen, três faixas, uma central e uma de cada lado dos urosternitos; metade apical do último urosternito com pubescência esbranquiçada. Olhos não-divididos, lobos oculares ligados por três fileiras de omatídios.

Dimensões em mm, ơ. Comprimento total, 11,312,9; comprimento do protórax, 1,5-1,8; maior largura do protórax, 1,1-1,4; comprimento do élitro, 8,7-9,9; largura umeral, 1,6-1,9.

Material-tipo. Holótipo ơ, BOLÍVIA, Santa Cruz: Buena Vista (4-6 km SSE, Hotel Flora \& Fauna), 27-29.X.2000, Wappes \& Morris col. (MNKM). Parátipo: mesma localidade e coletores do holótipo, ơ, 23-26.X.2000 (MZSP).

Discussão. Aerenicopsis angaibara sp. nov. assemelha-se a $A$. virgata (Pascoe, 1878) e a $A$. rufoantennata (Breuning, 1974) pelos olhos com três fileiras de omatídios entre os lobos e espinho elitral curto; distingue-se pelos antenômeros basais pretos e os demais (a partir do IV) avermelhados e pela pubescência dos urosternitos. Em A. virgata, as antenas são pretas, os lados dos urosternitos apresentam áreas glabras de dimensões gradativamente menores do I ao III e lados do IV e $\mathrm{V}$ com pubescência densa. Em A. rufoantennata o escapo é preto e o pedicelo e flagelômeros são vermelho-alaranjados; a pubescência amarelada densa ocupa os lados e o meio dos urosternitos e as áreas glabras laterais são menores.

Aerenicopsis irumuara sp. nov.

(Fig. 4)

Etimologia. Tupi, irumuara = companheiro. Alusivo à semelhança com $A$. mendosa.

Tegumento castanho-escuro. Pubescência corporal relativamente esparsa. Pubescência esbranquiçada adensada no occipício e numa faixa da região anterior da emarginação dos olhos até a margem anterior do protórax. Lados do protórax com faixa de pubescência esbranquiçada, densa. Pronoto com pubescência esbranquiçada convergindo de cada lado para o centro, constituindo duas faixas estreitas de cada lado de uma linha central, glabra. Élitros com pubescência esbranquiçada densa: faixa sutural, faixa dos úmeros até o quarto basal, curva para a sutura; faixa lateral junto à margem no terço basal continuada obliquamente até a sutura no terço apical, contornando uma área mais escura, lateral; terço apical. Pontuação dos élitros grossa e contrastante com a pubescência esbranquiçada. Na face ventral, a pubescência branca reveste a metade superior dos metepisternos, os mesepimeros, área anterior dos metepisternos, faixa curva nos lados do metasterno, faixas estreitas nos urosternitos: uma centro-longitudinal e uma de cada lado, oblíqua, do centro para as margens posteriores dos urosternitos I-IV; pubescência branca nos lados do urosternito V. Lobos oculares superiores separados dos inferiores por uma fileira de omatídios. Espinho no ápice elitral evidente.

Dimensões em mm, respectivamente $6 / \%$. Comprimento total, 13,9-14,1/14,2-15,8; comprimento do protórax, 1,4-1,5/1,7-1,8; maior largura do protórax, 1,61,8/1,5-1,6; comprimento do élitro, 10,9-11,0/11,1-12,5; largura umeral, 2,4-2,5/2,4-2,9.

Material-tipo. Holótipo $\varsubsetneqq$, GUATEMALA, Sololá: Lago Atitlan $\left(14^{\circ} 45^{\prime} \mathrm{N}, 91^{\circ} 10^{\prime} \mathrm{W}\right)$, X.2002, S. Neser \& Heystek col., adultos coletados em ramos de Lantana sp., Verbenaceae 

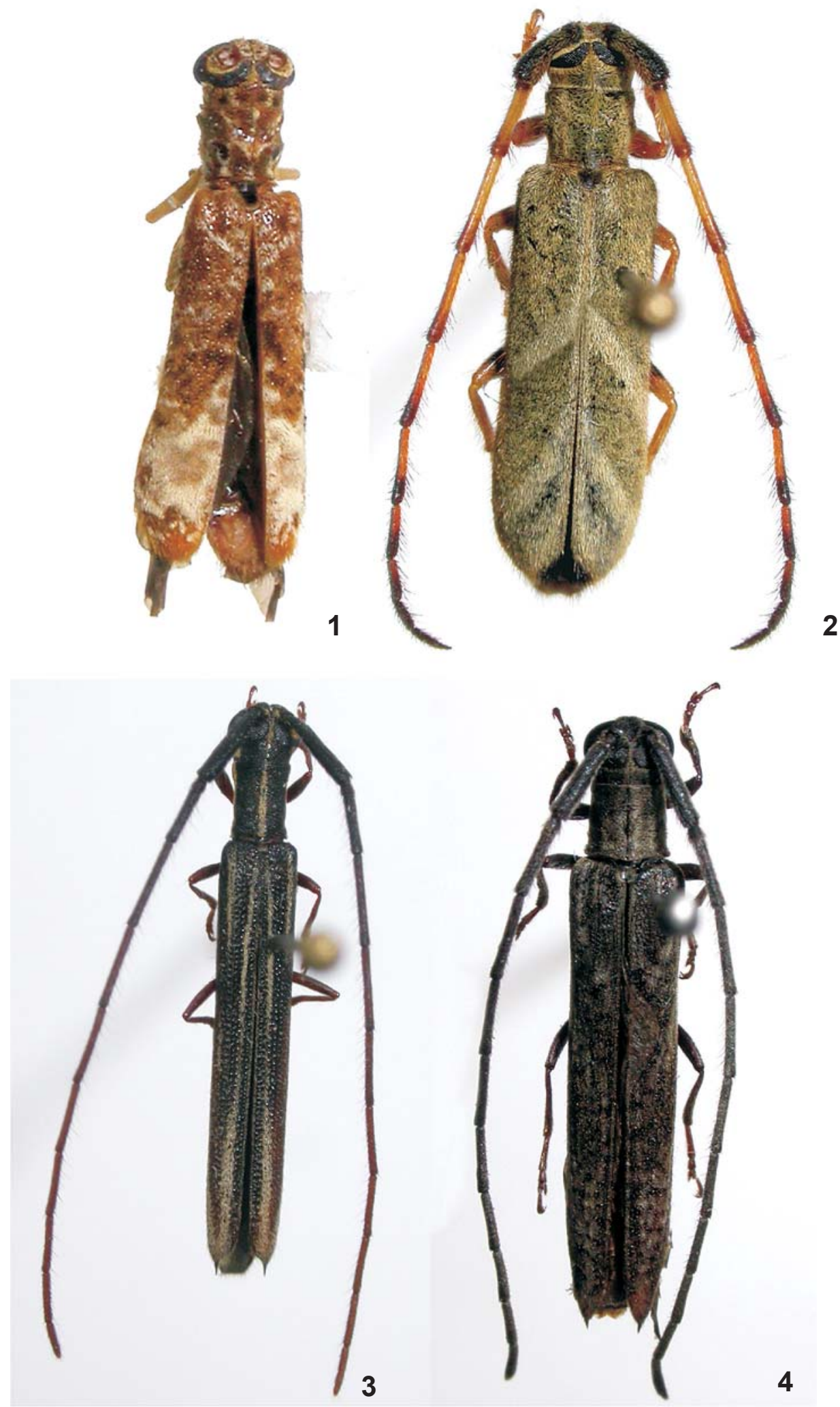

4

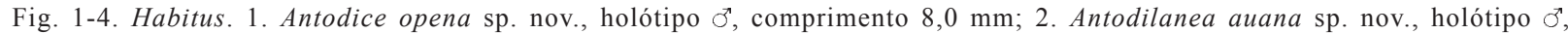
comprimento $11,0 \mathrm{~mm}$; 3. Aerenicopsis angaibara sp. nov., parátipo o', comprimento $12,9 \mathrm{~mm}$; 4. Aerenicopsis irumuara sp. nov., holótipo \&, comprimento $15,8 \mathrm{~mm}$. 
(SANC). Parátipos: mesmos dados do holótipo, $3 \&$, $\sigma^{\prime}$ (SANC), ơ, \& (MZSP), \& (MCNZ).

Discussão. Aerenicopsis irumuara sp. nov. assemelha-se a $A$. hubrichi Bruch, 1925 e $A$. mendosa Martins \& Galileo, 1998 pelos lados do pronoto revestidos de pubescência esbranquiçada sem constituir faixa. Diferencia-se de A. hubrichi pelos olhos com uma fileira de omatídios entre os lobos; pelo espinho sutural curto e pela pubescência esbranquiçada pouco adensada; de $A$. mendosa, pelo espinho sutural dos élitros curto e agudo. Aerenicopsis hubrichi tem os olhos divididos e as faixas de pubescência branca, densa, bem definidas. O espinho apical dos élitros de $A$. mendosa é curto, mas não agudo.

\section{Suipinima gen. nov.}

Etimologia. Tupi, suí $=$ sem; pinima $=$ mancha. Alusivo aos élitros sem manchas.

Espécie-tipo, Suipinima suturalis sp. nov.

Fronte mais larga que o diâmetro apical do escapo. Mandíbulas com ápice bífido. Olhos nãodivididos. Lobos oculares superiores contíguos $(S$. excentrica) ou separados por largura equivalente a duas ou três fileiras de omatídios. Antenas mais longas do que o corpo. Escapo apenas mais curto do que o antenômero III. Flagelômeros não-espessados. Protórax mais largo do que longo ( $S$. suturalis, S. marginalis, $S$. excentrica) ou tão largo quanto longo $(S$. una, $S$. pitanga); arredondado nos lados ou com gibosidade mediana. Élitros com tegumento preto ou acastanhado, sem manchas de pubescência branca ou amarelada e sem pontos contrastantes; extremidades elitrais arredondadas. Metafêmures atingem a base ou a margem apical do urosternito II. Apêndice interno das unhas tarsais reduzido e largo ou longo, subigual ao externo.

Discussão. Suipinima gen. nov. reúne espécies que diferem em alguns aspectos. A forma do protórax é bem arredondada nos lados, como em $S$. excentrica, mas também pode ter lados subparalelos ou levemente mais largos anteriormente e providos de gibosidade lateral, por exemplo, em S. una. As tíbias podem ser normais ou engrossadas e providas de pêlos densos (S. una). As garras tarsais têm o dente interno largo (S. suturalis) ou podem ser acentuadamente bífidas com o dente interno subigual ao externo.

Suipinima assemelha-se a Antodice pelos lobos oculares superiores próximos entre si ou contíguos e difere pelos élitros sem manchas de pubescência branca ou amarelada.

\section{Chave para as espécies de Suipinima}

1. Protórax tão longo quanto largo, com gibosidade nos lados

Protórax mais largo que longo, com os lados arredondados

2(1). Élitros com friso sutural claro, contrastante; metafêmures pretos com mancha anteapical alaranjada; metatíbias não-intumescidas, com lados paralelos em toda a extensão e de mesma largura que os metatarsos (fig. 5). Bolívia ....

S. pitanga sp. nov.

Élitros pretos, unicolores, sem pubescência clara no friso sutural; metafêmures pretos; metatíbias engrossadas em toda a extensão e mais largas que os metatarsos (fig. 6). Bolívia. S. una sp. nov.

3(1). Protórax alaranjado com base transversalmente escurecida; centro do pronoto uniformemente coberto por pubescência amarelada e longa; antenômero III, VIII e IX alaranjados; antenômeros X e XI pretos; lobos oculares superiores contíguos. Equador

S. excentrica (Galileo \& Martins, 1992) Protórax preto; meio do pronoto preto ou castanho, lados com faixas longitudinais de pubescência amarelada; antenômeros III, VIII a XI pretos; lobos oculares superiores afastados entre si ...................................... 4

4(3). Escapo, pedicelo e antenômero III pretos; epipleuras com pêlos amarelados somente sobre o friso marginal; metepisternos cobertos por pubescência branca, densa; tíbias e tarsos pretos (fig. 7). Brasil (Rondônia), Bolívia .

S. suturalis sp. nov.

Escapo amarelado com ápice preto; pedicelo e antenômero III pretos com anel basal amarelado; toda a metade inferior da epipleura com pêlos amarelados; metepisternos cobertos por pubescência amarelada e esparsa; tíbias e tarsos acastanhados (fig. 8). Bolívia ...................... S. marginalis sp. nov.

\section{Suipinima pitanga sp. nov. \\ (Fig. 5)}

Etimologia. Tupi, pitanga = vermelho; alusivo à cor do disco pronotal.

Fronte e vértice com tegumento avermelhado; região atrás dos lobos oculares inferiores preta; cabeça revestida por pubescência amarelada; lobos oculares superiores separados entre si por largura equivalente a três fileiras de omatídios. Escapo preto na metade externa e alaranjado na metade interna; pedicelo e antenômeros alaranjados com o ápice escurecido. Em alguns exemplares, pedicelo e antenômeros III-VII amarelo-alaranjados; antenômeros VIII-IX com ápice preto; X-XI pretos. Pronoto vermelho com base transversalmente preta; partes laterais do protórax e prosterno, pretos. Lados do pronoto com faixa de pilosidade branca, longa. Élitros pretos; friso sutural avermelhado recoberto por pubescência branca; metade anterior da declividade lateral com tegumento avermelhado que pode se estender até a extremidade elitral. Profêmures alaranjados com ápice preto ou com base e ápice pretos; meso- e metafêmures pretos com mancha anteapical alaranjada; protíbias pretas na face anterior e avermelhadas na face posterior. Meso- e metatíbias pretas. Tarsos pretos; dente interno das garras tarsais quase tão longo quanto o externo. 
Dimensões em $\mathrm{mm}$, respectivamente $\sigma^{7 / 9}$. Comprimento total, 7,9/9,0; comprimento do protórax, $1,1 / 1,2$; maior largura do protórax, 1,1/1,3; comprimento do élitro, 5,9/6,7; largura umeral, 1,6/1,7.

Material-tipo. Holótipo $\circlearrowleft$, BOLÍVIA, Santa Cruz: Buena Vista (4-6 km SSE, Hotel Flora \& Fauna), 22-31.X.2002, Wappes \& Morris col. (MNKM). Parátipos: BOLÍVIA, Santa Cruz: Buena Vista, \&, XI-XII.1992, R. Clarke col. (ACMB); (3,7 km SSE, Hotel Flora \& Fauna, $430 \mathrm{~m})$, o, 23-26.X.2000, M. C. Thomas col. "tropical transition forest" (MZSP).

Discussão. Suipinima pitanga sp. nov. assemelha-se a $S$. una sp. nov. pelo protórax subquadrangular e com gibosidade nos lados. Distingue-se pelo friso sutural dos élitros amarelo, contrastando com o restante do colorido preto; pelos metafêmures com uma mancha anteapical alaranjada. Em S. una os élitros e os metafêmures são unicolores.

\section{Suipinima una sp. nov.}

(Fig. 6)

Etimologia. Tupi, una = preto; alusivo à cor dos élitros. Cabeça e protórax avermelhados. Escapo, pedicelo e antenômero III (menos anel basal), ápice do VIII e metade apical do IX, X-XI pretos. Anel basal do antenômero III e antenômeros IV-VII alaranjados. Pro- e mesocoxas amareladas. Élitros, ponta do processo prosternal, esternos torácicos, urosternitos, pernas posteriores, tíbias e tarsos pretos. Profêmures pretos com o ápice amarelado no lado externo; no lado interno, amarelados menos na base. Mesofêmures pretos com pequena porção apical amarelada.

Vértice com pubescência branco-amarelada. Antenas das fêmeas apenas mais curtas que o corpo. Protórax mais largo anteriormente do que na base, com gibosidade evidente no meio dos lados. Pronoto com faixa de pubescência branco-amarelada nos lados. Tíbias, especialmente as posteriores, engrossadas e densamente pubescentes.

Dimensões em mm, respectivamente $3 / 9$. Comprimento total, 7,7-9,4/8,7-9,5; comprimento do protórax, 1,0-1,3/1,2-1,4; maior largura do protórax, 1,2-1,5/1,4-1,5; comprimento do élitro, 5,8-7,4/6,4-7,3; largura umeral, 1,7$2,2 / 2,0-2,2$.

Material-tipo. Holótipo ơ, BOLÍVIA, Santa Cruz: Buena Vista (4-6 km SSE, Hotel Flora \& Fauna), 1-14.II.2003, R. Clarke col. (MNKM). Parátipos: mesmos dados do holótipo, § (ACMB); mesma procedência $(3,7 \mathrm{~km}$ SSE Hotel Flora \& Fauna, $430 \mathrm{~m})$, 5-15.XI.2001, M. C. Thomas \& B. K. Dozier col. ("black light trap, tropical transition forest") (FSCA); ditto, ơ, \&, 15-22.XI.2001, B. K. Dozier (MZSP, MCNZ); ditto, (4-6 km SSE), \&, 2-12.II.2000, J. E. Wappes col. (ACMB).

Discussão. Suipinima una sp.nov. diferencia-se das demais espécies do gênero pelas tíbias engrossadas e densamente pubescentes.

\section{Suipinima suturalis sp. nov. (Fig. 7)}

Etimologia. Latim, suturalis $=$ sutural; alusivo à faixa de pubescência branco-amarelada na sutura elitral.

Tegumento de maneira geral preto; escapo, pedicelo e antenômero III pretos; tegumento amarelado: antenômeros IV e V (menos ápice, preto), metade do VI, anel basal do VII, profêmures (menos centro da parte inferior, preto), ápice dos meso- e metafêmures. Tarsômeros V pretos. Pubescência branco-amarelada: fronte, borda dos olhos, faixa atrás dos lobos oculares inferiores continuada pelos lados do protórax, friso sutural, metepisternos, lados e faixa transversal na margem posterior dos urosternitos I-IV. Lobos oculares superiores separados por distância equivalente, nos machos, a duas fileiras de omatídios e, nas fêmeas, a três fileiras de omatídios. Protórax arredondado nos lados.

Dimensões em $\mathrm{mm}$, respectivamente $\sigma^{7 / q}$. Comprimento total, 10,5-11,2/15,0; comprimento do protórax, 1,3-1,5/1,7; maior largura do protórax, 1,7-1,8/ 2,4; comprimento do élitro, 8,0-8,6/12,0; largura umeral, $2,3-2,4 / 3,0$.

Material-tipo. Holótipo đ̆, BRASIL, Rondônia: Ariquemes (62 km S, Fazenda Rancho Grande), 8.XI.1994, C. W. \& L. B. O’Brien col., luz ultravioleta e de vapor de mercúrio (FSCA). Parátipos: mesmos dados do holótipo, Ő, (MZSP). BOLÍVIA, Santa Cruz: Buena Vista (4-6 km SSE, Hotel Flora \& Fauna), 2 o', 16-31.XII.2002, R. Clarke col. (ACMB, MZSP); mesma localidade $(3,7 \mathrm{~km}$ SSE, Hotel Flora \& Fauna, $430 \mathrm{~m})$, o', 15-22.XI.2001, B. K. Dozier col., "black light trap, transition forest" (ACMB); ditto, f, 5-15.XI.2001, M. C. Thomas \& B. K. Dozier col., "black light trap, transition forest"(FSCA); ditto, (405 m, 17²9,949'S, 6333,152' W), o, 5-15.XI.2001, M. C. Thomas \& B. K. Dozier col., "tropical transition forest" (MCNZ); Santa Cruz, f, 20.XII.1958, M. Alvarenga col. (MNRJ).

Discussão. Suipinima suturalis sp. nov. assemelha-se a $S$. marginalis sp. nov. pelo padrão de colorido e pelas faixas de pubescência amarelada na cabeça e no protórax. Distingue-se pelas antenas longas que atingem o ápice elitral na extremidade do antenômero VIII e pela pubescência amarelada nos élitros restrita ao friso sutural.

\section{Suipinima marginalis sp. nov. (Fig. 8)}

Etimologia. Latim, marginalis = marginal; alusivo à cobertura de pubescência branca nas margens dos élitros.

Colorido geral acastanhado. Faixa atrás dos olhos acastanhada. Pubescência amarelada: fronte, largamente no vértice, deixa apenas mancha triangular, occipital, do tegumento de fundo, lados do protórax, escutelo, longitudinalmente na sutura e na margem dos élitros. Pubescência branca: prosterno e mesosterno. Profêmures amarelados; protíbias amareladas e, na face anterior, pretas. Meso- e metafêmures amarelados, indistintamente acastanhados no meio. Meso- e metatíbias amareladas com a região apical mais acastanhada. Tarsômero $\mathrm{V}$ amarelado na base. Lobos oculares superiores separados por distância equivalente a três fileiras de omatídios. Protórax com lados arredondados.

Dimensões em mm, $\circlearrowleft$. Comprimento total, 8, 0-9,8; comprimento do protórax, 1,4-1,7; maior largura do protórax, 1,8-2,1; comprimento do élitro, 5,9-7,2; largura umeral, 2,0-2,5.

Material-tipo. Holótipo đ̆, BOLÍVIA, Santa Cruz: Buena Vista (4-6 km SSE, Hotel Flora \& Fauna), 21 24.XI.2003, J. Wappes, Morris \& Nearns col. (MNKM). Parátipo: mesma localidade do holótipo, §, 17-19.X.2000, Wappes \& Morris col. (MZSP). 

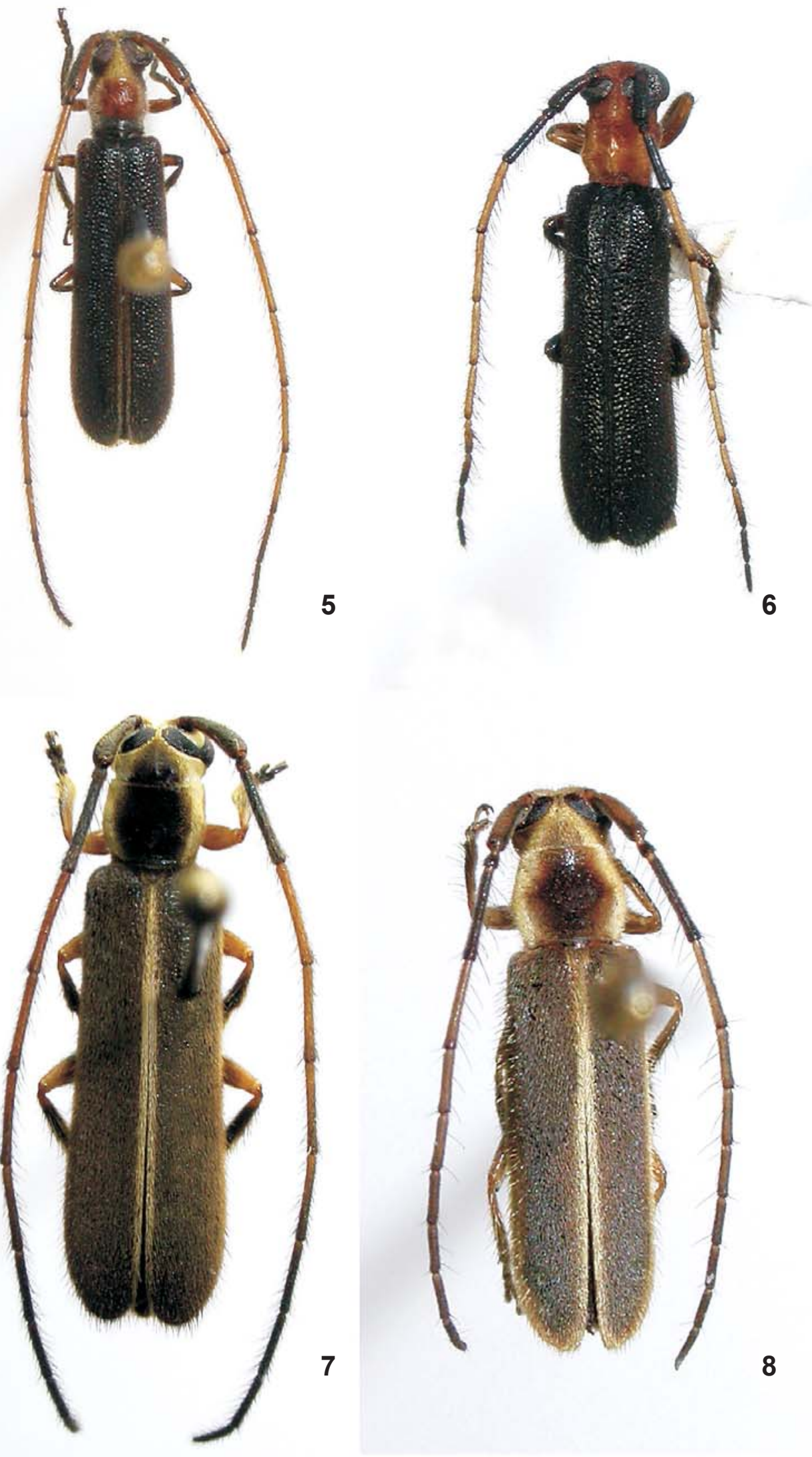

Figs. 5-8. Habitus. 5. Suipinima pitanga sp. nov., holótipo ơ, comprimento 7,9 mm; 6. Suipinima una sp. nov., holótipo $\sigma$, comprimento $7,7 \mathrm{~mm}$; 7. Suipinima suturalis sp. nov., parátipo $\sigma^{\prime}$, comprimento $11,2 \mathrm{~mm}$; 8. Suipinima marginalis sp. nov., holótipo ऊ’, comprimento $8,0 \mathrm{~mm}$. 
Discussão. S. marginalis sp. nov. distingue-se de $S$. suturalis sp. nov. pelo comprimento das antenas que atingem o ápice elitral no ápice do antenômero X e os frisos sutural e marginal cobertos por pubescência amarelada.

Agradecimentos. Aos curadores das coleções, J. E. Wappes, Miguel A. Monné e E. Grobbelaar, pelo empréstimo de material. A Rafael Santos de Araujo (MCNZ), pela execução das fotografias.

\section{REFERÊNCIAS BIBLIOGRÁFICAS}

Martins, U. R. \& Galileo, M. H. M. 1998. Revisão da tribo Aerenicini Lacordaire, 1872 (Coleoptera, Cerambycidae, Lamiinae). Arquivos de Zoologia, São Paulo, 35(1):1133.

2003. Novas espécies e nota sobre Lamiinae (Coleoptera, Cerambycidae) neotropicais da coleção Arriagada, Santiago, Chile. Revista Brasileira de Entomologia, Curitiba, 47(4):615-620. 